\title{
Modelling the Emergence and Dynamics of Social and Workplace Segregation*
}

\author{
Mohamed Abdou and Nigel Gilbert \\ Centre for Research in Social Simulation, University of Surrey, \\ Guildford GU2 7XH, United Kingdom \\ m.abdou@surrey.ac.uk,n.gilbert@surrey.ac.uk
}

\begin{abstract}
The relationship between social segregation and workplace segregation has been traditionally studied as a one-way causal relationship mediated by referral hiring. In this paper we introduce an alternative framework which describes the dynamic relationships between social segregation, workplace segregation, individuals' homophily levels, and referral hiring. An agent-based simulation model was developed based on this framework. The model describes the process of continuous change in composition of workplaces and social networks of agents, and how this process affects levels of workplace segregation and the segregation of social networks of the agents (people). It is concluded that: (1) social segregation and workplace segregation may coevolve even when hiring of workers occurs mainly through formal channels and the population is initially integrated (2) majority groups tend to be more homophilous than minority groups, and (3) referral hiring may be beneficial for minority groups when the population is highly segregated.
\end{abstract}

Keywords: social networks, segregation, referral hiring, agent-based simulation.

\section{Introduction}

According to the Contact Hypothesis (Amir 1969; Allport 1954), contact between different social (ethnic, racial and/or religious) groups promotes trust, tolerance and social integration. When individuals' social networks become more segregated (that is, social relationships are formed with others of similar gender, race, ethnicity, and/or religion) the chance of their contacts crossing their group's boundary is reduced, leading to increasing levels of stereotyping and intolerance.

Similarly, workplace segregation may also reduce the chance of intergroup contact. In addition to these negative social effects, workplace segregation may have negative economic consequences. For example, it may introduce high levels of income and employment inequality among social groups (Carrington \& Troske 1998; Glass 1990; Granovetter 1995; Tassier \& Menczer 2008). Moreover, workplace segregation may

* An earlier version of this paper was presented in the annual conference of European Social Simulation Association (ESSA), Brescia, September 2008. 
also affect the economic system as a whole through its effects on the efficiency of allocating workers to jobs (Becker 1971).

Although both act as barriers against intergroup contact, workplace segregation and social segregation (segregation of individuals' social networks) have been studied as two separate areas of research. Moreover, research (especially on workplace segregation) has focused mainly on the consequences (for example income and employment inequality) rather than the determinants and dynamics of segregation.

In research on social segregation, the homophilous attitudes of individuals have been considered the main determinant of segregation (Amir 1969; Allport 1954). The homophily principle implies that people are attracted by nature to others similar to themselves, and are more likely to create social ties with them as described by the proverb "birds of a feather flock together" (McPherson et al. 2001). This similarity among individuals may be evaluated on the basis of gender, race, religion and ethnicity or other factors.

On the other hand, in research on workplace segregation, referral hiring (hiring through social or familial contacts) has been considered the main source of segregation. Using social and familial contacts to search for jobs is a widespread practice. Granovetter $(1973,1995)$ found that more than half of workers in the U.S. knew about their jobs through informal channels (friends, relatives, and other social contacts). In a recent study conducted by the authors about workplaces and social networks in Egypt, 65 percent of workers used these informal methods of seeking employment. Elliott (2001) explains how referral hiring could promote workplace segregation:

\section{"[Referral hiring] creates a built-in bias toward incumbents: members of a particular ethnic group concentrate in particular jobs and when new employment opportunities become available at their workplace, they pass this information along to [their] social contacts, often of the same race and ethnic background"(p. 401).}

According to Elliot's analysis, the relationship between social segregation and workplace segregation has been assumed to be a one-way causal relationship. In this relationship, the independent variable is the level of social segregation and the dependent variable is the level of workplace segregation, with level of referral hiring as a moderating variable (see for example Elliott 2001; Tassier 2005; Tassier \& Menczer 2008). When using referral hiring for employment, the effect of segregated individual social networks would be expected to increase workplace segregation.

In the current work, we argue that the relationship between social and workplaces segregation can also go in the other direction; that is, workplace segregation can affect (as well as be affected by) social segregation. Empirical literature confirms that high percentage of our social relations are embedded in organizations (Grossetti 2005). Organizations contribute to the construction of the pool of candidates whom people might create social relations with. Thus, when these pools become segregated social segregation is promoted and vice versa.

In this paper, we introduce a general framework to study the dynamic and reciprocal relationships between social segregation and workplace segregation, homophily levels, and referral hiring. An agent-based simulation model for the labour market has been developed based on this framework. The model creates an artificial 
society where agents (people) use their social networks to search for jobs. As simulated time passes, agents change their social networks by creating new social links (ties) with each other while other links dissolve. Also, the composition of workplaces (the proportion of workers from different societal groups) may change through the turnover of workers. The model describes this process of continuous change in the composition of workplaces and social networks of agents, and how it affects levels of workplace segregation and the segregation of the social networks of agents.

We argue here that agent-based modelling ( $\mathrm{ABM}$ ) is an appropriate methodology that fits well the purpose of the current work. Our main objective is to understand the co-emergence and dynamics of two complex phenomena; that is, social and workplace segregation. Both involve non-linear interactions among heterogeneous agents on different levels (for example, workers and firms), which makes computational models more flexible than mathematical and statistical models (Gilbert \& Troitzsch 2005). Besides, agents provide a good analogy to individuals; therefore, $\mathrm{ABM}$ is more appropriate than other computational techniques when dealing with interactions involving people. For these reasons ABM has been successfully used in segregation research since the famous Schelling (1971) model of residential segregation.

This paper is organized as follows. A brief review of related research is presented in Section 2. In section 3, we introduce the proposed framework for the relationship between social segregation and workplace segregation. Then, in Section 4 , the agentbased simulation model is presented. The results of the simulation model are discussed in Section 5. In Section 6, we discuss how the model was validated against different sources of empirical data. Finally, the conclusion and summary of the main findings are presented in Section 7.

\section{Review of Related Research}

Granovetter's seminal work $(1973,1995)$ documented the widespread use of referral hiring and emphasized the importance of social ties, especially weak ties, as a source of job information and attainment. Most research after Granovetter focused on the role of social networks for the transmission of job information and opportunities, and how this affects job attainment and employment inequality (for a review of this research see Ioannides \& Loury 2004).

Using agent-based simulation Calvó-Armengol and Jackson $(2007,2004)$ showed that employment is positively correlated across time and agents. That is, the employment statuses of path-connected agents are positively correlated. When some agents are employed, then it is more likely that other agents in contact with them will receive job information from them. This holds even in different points in time. Similar results were obtained by Krauth (2004) who showed that the likelihood of employment is positively correlated with the size of an individual's social network and the employment rates of those in contact with them.

Calvó-Armengol and Jackson also found that unemployment exhibits duration dependence; that is, the probability of obtaining a job decreases with the length of time that an agent has been unemployed. They examined inequality between two 
arbitrary groups and showed that when one group starts with a worse employment status, then that group's drop-out rate will be higher and their employment prospects will be persistently below that of the other group.

Little research has focused on the determinants of workplace segregation, and even Calvó-Armengol and Jackson defined social networks exogenously with no mention of the effect of workplace segregation on social segregation. For example, Tassier and Menczer (2008) introduced an agent-based simulation model to study the effect of referral hiring on group level inequality for a given social network structure and social segregation. Building on Watts and Strogatz's small world model (Watts 1999; Watts \& Strogatz 1998), Tassier and Menczer introduced a method for controlling network structure and level of social segregation. The results of the simulation showed that more random social networks produces higher employment rates than less random social networks if the population is integrated or information flows about job vacancies are random. However, if the population is highly segregated and information flows about job vacancies are non-random then less random social networks have higher employment rates than more random social networks.

Using a different methodology, and based on an implicit assumption of complete social segregation, Tassier (2005) developed a Markov model to study the effects of referral hiring on workplace segregation and inequality between two social groups. In this model, the proportion of the minority group in the firm determines its state, and the transition probabilities are determined by the proportion of unemployed individuals from each group and the current state of the firm. The model showed that the level of workplace segregation increases with the increase of referral hiring, and a complete segregation occurs when all workers find their jobs by referral hiring. Moreover, Tassier argued that referral firing does not produce group-level employment inequality. Tassier (2008) used this Markov model to study how referral hiring produced gender segregation among employees at US colleges and universities.

Models of strategic network formation focus on how expectations about labour market outcomes influence individuals' decisions regarding their social networks (for a review of these models see Jackson 2004). For example, Gemkow and Neugart (2008) have recently developed an agent-based model of the labour market where agents (workers) invest some of their resources into building and maintaining their social networks as an insurance device against future job losses. They found that larger variability in firms' labour demand reduces the workers' investment into their social networks which leads to lower inequality. However, none of this strategic network formation research focused on segregation.

\section{A General Framework for the Relationship between Social and Workplace Segregation}

Figure 1 summarises the proposed framework to study social and workplace segregation. In this framework, reciprocal causal relationships are assumed to exist between social segregation, workplace segregation, and individuals' homophily levels (each arrow in Figure 1 indicates positive causal relationships between the variables at its two ends). 


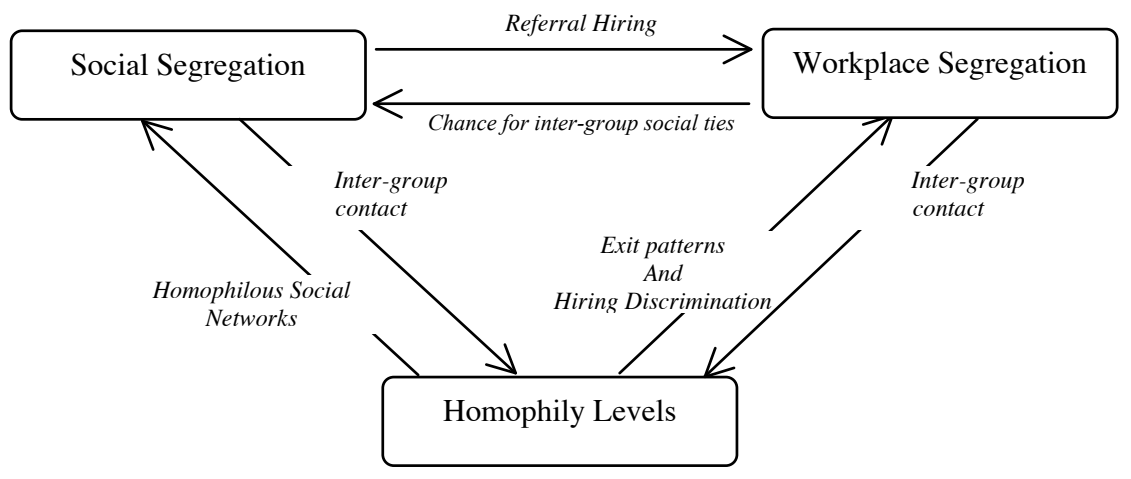

Figure 1. The proposed framework to study the relationship between social and workplace segregation.

For example, social segregation may affect workplace segregation. When firms tend to hire new workers through referrals, especially referrals from other existing workers (insider referrals), and when social networks of people tend to be segregated, this promotes workplaces segregation. As explained earlier, most previous research has focused on this effect of social segregation on workplace segregation (see for example Elliott 2001; Mouw 2002; Tassier 2005; and Tassier \& Menczer 2008). On the other hand, when workplaces become more segregated, the chance for people from different social groups to work together and create social relations at work is reduced, and this increases social segregation (given the empirical evidence that a high percentage of social relations are created at workplaces (Grossetti 2005)).

Empirical data gathered by the authors (see Section 5) about labour market and social networks in Egypt in 2007 support this hypothesised reciprocal relation between social and workplace segregation. The number of Coptic friends of Muslim workers was strongly correlated with the proportion of Coptic worker in his firm.

The relationship between homophily levels and social segregation is not difficult to explain, and it is a direct application of the contact hypothesis (Amir 1969; Allport 1954). By definition, an individual's homophily level is a bias towards creating social ties with similar others. So, higher levels of homophily coincide with higher levels of social segregation. On the other hand, when social networks become more integrated, individuals have a higher chance to have contact with others from different social groups, and this hinders their homophilous attitudes.

Many empirical studies (for example: Ellison \& Powers 1994; Emerson et al. 2002; Robinson 1980; Sigelman \& Welch 1993; Williams 1964; Yancey 1999) have documented decreasing levels of prejudice and stereotyping with more intergroup contact given a set of favourable conditions (for example, equal status of contact groups, institutional support, and pursuit of common goals). For example Emerson et al (2002) found that those who had experienced prior interracial contact in schools and neighbourhoods were more likely, as adults, to have more racially diverse general social groups and friendship circles.

Firnally, the relationship between homophily levels and workplace segregation can be described as follows. Individuals' homophily levels may affect workplace 
segregation through their effects on the exit patterns of workers and hiring discrimination. As empirical studies show (for example Sørensen (2004)), workers with high levels of homophily tend to stay longer in segregated workplaces where their groups are over-represented than in other workplaces. Also, higher homophily levels among employers promotes hiring discrimination (that is, employers' preferences to hire workers of the same social group as their own (Becker 1971)), and this increases workplace segregation. In turn, workplace segregation may affect the homophily levels of individuals. Segregated workplaces reduce the chance for intergroup contact, which promotes homophilous attitudes and vice versa.

\section{An Agent-Based Simulation Model}

Based on the framework presented in the previous section, we present an agentbased model which describes the dynamic relationship between the main variables: social segregation, workplace segregation, homophily levels, and referral hiring. First, we describe the model's specification and then some of the simulation results.

\subsection{Agents}

The model creates an artificial society of $N$ equally-qualified agents (representing persons). Each agent belongs to one of two different social groups; for simplicity, we call them Red and Green. Assume that the Red group is the minority, and its proportion in the society is $P$ (where $0<P<0.5$ ).

\subsection{Social Networks}

A Social Network is a "set of people who are most likely to be sources of a variety of rewarding interactions, such as discussing a personal problem, borrowing money, or social recreation" (McCallister \& Fischer 1983:78). Each agent has its own egocentric social network. For each agent, the maximum possible size of its social network (maximum number of alters at one time) is $S_{i}, i=1,2, \ldots, N$.

Homophily Levels. Agents create social links with each other based on their homophily levels, $h_{i} \in[0,1]$. An agent's homophily level indicates its bias to create social links with other agents of the same colour (group) as its own. For example, a Red agent would create a social link to another Red agent with the following probability $^{\mathbf{1}}$ (and it creates a link to a Green agent with the complement probability):

\footnotetext{
${ }^{1}$ Analogously, Prob (Green to Green $)=\left\{\begin{array}{cc}(1-p)+h p & \text { if } \mathrm{p}<1 \\ 0 & \text { otherwise }\end{array}\right.$
} 


$$
\operatorname{Prob}(\text { Red to Red })=\left\{\begin{array}{cc}
p+h(1-p) & \text { if } \mathrm{p}>0 \\
0 & \text { Otherwise }
\end{array}\right.
$$

In formula (1), (small) $p$ refers to the proportion of Red agents available within the context of link creation. For example, when a Red agent joins a workplace, and it is about to create a social link to one of the existing co-workers, $p$ would refer to the proportion of other Red workers (who are not linked to the agent) in that workplace.

Based on formula (1), with $h=0$, all links are created at random, and all agents will have the same probability $p$ to create links with Red agents and the probability $1-p$ to create links with Green agents. With $h=1$, each agent would create links only with other similar agents (if such agents are available, otherwise with other agents of the other colour).

Agents are initialized with a zero homophily level. However, an agent's homophily level changes over time, and is assumed to depend - in addition to its current level on five factors: (1) composition of its social network, (2) average homophily level of alters in its social network, (3) composition of its workplace, (4) average homophily level of its workmates, and (5) overall average homophily of all agents in society. Thus, for a Red agent, its homophily level at time $t+1, h_{t+l}$, can be written as a weighted average of its homophily level $h_{t}$ and the effects of these five factors as:

$$
\begin{aligned}
h_{t+1}= & {\left[h_{t}+\alpha_{1}\left(p_{n}-P\right) /(1-P)+\alpha_{2} \text { (mean homophily of alters) }+\alpha_{3}\left(p_{w}-P\right) /(1-P)\right.} \\
& +\alpha_{4} \text { (mean homophily of workmates) }+\alpha_{5} \text { (overall mean homophily of } \\
& \text { all agents) }] /\left(1+\alpha_{1}+\alpha_{2}+\alpha_{3}+\alpha_{4}+\alpha_{5}\right)
\end{aligned}
$$

where $h_{t}$ is the agent's homophily level at time $t, p_{n}$ is the proportion of alters of Red colour in agent's social network, $p_{w}$ the proportion of Red workmates, and $\alpha_{1}$, $\alpha_{2}, \alpha_{3}, \alpha_{4}$ and $\alpha_{5}$ are constants reflecting the relative importance of the associated components.

Directed vs. Undirected Links. In forming their social networks agents create directed (asymmetric), rather than undirected (symmetric) social links with each other to represent the potential asymmetry in the evaluation of social links, and the asymmetry in job knowledge and access (Tassier 2005).

Origins of Social Relations. In line with Fischer (1982), agents create social links through three sources: workplaces, other friends/relatives (other links) and random acquaintances. At each time step of a simulation run, each "working" agent has a probability $L_{W}$ to create a social link to one of its co-workers. Also, at each time step, each agent has a probability $L_{N}$ to create a new link with another agent through its existing social network (in other words, with another agent who is already linked with one of the agent's social network), and a probability $L_{R}$ to create a new link with another agent at random. The actual values of the probabilities $L_{W}, L_{N}$, and $L_{R}$ that will be used in the simulation (as will appear in Table 1) are based on our collected data about social networks and workplaces in Egypt (and are supported by Grossetti (2005)) which showed that around three fifths of social relations develop within workplaces, while random acquaintances are very small proportion. Finally, to keep the initial distribution of links constant among agents, all extra links (more than $S_{i}$ ) will be removed at random. 


\subsection{Workplaces and Jobs}

Our artificial labour market includes a number of firms, $F$, each of which having a number of jobs $\left(\theta_{f}\right)$. We assume that all jobs are identical (so, any agent can do any job with the same efficiency). Each firm has a "colour" which indicates the group identity of its owner/manager (employer). Suppose that the proportion of Red firms is $P$. Hiring discrimination for a firm $f, D_{f}$, is defined as the mean homophily level of its workers multiplied by a regulating scalar discrimination-const. Besides, each firm, $f$, has a total of $t_{f}$ agents (workers), which can be divided into $r_{f}$ Red agents and $g_{f}$ Green agents, such that $t_{f}=r_{f}+g_{f}$. Let $p_{f}=r_{f} / t_{f}$ be the proportion of the minority (Red) group inside this firm. Finally, let $T=\sum_{f} t_{f}$ denote total number of currently working agents.

Hiring Process. At each time step each firm hires a number of agents (workers) to fill its vacant jobs. Firms can hire new agents either through referrals from current workers (with probability $R$ ) or through formal channels (with probability 1-R). If a firm decides to hire a worker through formal methods it simply picks one of the unemployed workers at random. In case of hiring through referrals from current workers, firms may practice hiring discrimination against the candidate workers. Let $Q$ represent the group of candidate workers, i.e., unemployed workers who have social links with at least one of the current workers in the firm. If no such workers exist, firms hire through formal channels. For example, a Red firm would hire a Red agent through referral with the probability:

$\operatorname{Prob}($ Red firm to hire Red worker through referral)=

$$
\left\{\begin{array}{cc}
p_{Q}+D_{f}\left(1-p_{Q}\right) & \text { if } p_{Q}>0 \\
0 & \text { Otherwise }
\end{array}\right.
$$

and it hires a Green agent with the complement probability, where $p_{Q}$ refers to the proportion of Red agents in the group $Q$.

Workers' Turnover. At each time step of the simulation run, each working agent has some probability to leave its workplace. This probability depends on the agent's homophily level, $h$, and its workplace composition (how different the proportion of its group inside the workplace, $p$, is from the overall group proportion in the society, $P$ ). For example, the probability of a Red agent to leave its workplace at any time step is given by:

$$
E_{R}=\beta(1+h(P-p))
$$

where $\beta$ is a constant regulating the speed of workers' turnover (for Green agents, $P$ and $p$ should be replaced by $(1-P)$ and (1-p) respectively in (4)). For an agent with zero-homophily, its probability to leave equals $\beta$ regardless of the proportion, $p$, of its group in the workplace. On the other hand, an agent with a non-zero homophily, $h$, would have an increasing probability to leave as its group's proportion $p$ inside the workplace decreases away from its overall proportion $\mathrm{P}$, and vice versa. 


\subsection{Statistics and Indexes}

We are particularly interested in measuring levels of social segregation and workplace segregation in addition to employment levels for minority and majority groups.

Index of Social Segregation. The segregation index, $S$, developed by Freeman $(1978: 416)^{2}$ is used to measure level of social segregation. $S$ measures the deviation of the distribution of links between two agents from different groups from the distribution expected when links are created at random:

$$
S=\left\{\begin{array}{cl}
\frac{E\left(e^{*}\right)-e^{*}}{E\left(e^{*}\right)} & \text { If and only if } E\left(e^{*}\right) \geq e^{*} \\
0 & \text { Otherwise }
\end{array}\right.
$$

where $E\left(e^{*}\right)$ is the expected number of links between two agents from different groups under the assumption that links are created at random, and $e^{*}$ is the actual number of such links.

$E\left(e^{*}\right)$ is given by (adapted from Freeman (1978:416)):

$$
E\left(e^{*}\right)=\frac{2 N L P(1-P)}{N-1}
$$

where $L$ is the total number of links in the global social network, and $N$ (number of agents) and $P$ (proportion of Red agents) are as defined before.

Indexes of Workplace Segregation. A modified version of the Gini index, $\hat{G}$, developed by Carrington and Troske (1997:406) will be used to measure workplace segregation. $\hat{G}$ measures the deviation of the distribution of workers from different social groups inside firms from random distribution (which is the case in which workers are randomly allocated to firms) and is given by:

$$
\begin{gathered}
\hat{G}=\left\{\begin{array}{lll}
\frac{G-G^{*}}{1-G^{*}} & \text { if } & G \geq G^{*} \\
\frac{G-G^{*}}{G^{*}} & \text { if } & G<G^{*}
\end{array}\right. \\
\text { where } G=\sum_{i=1}^{F} \sum_{j=1}^{F} t_{i} t_{j}\left|p_{i}-p_{j}\right| / 2 T^{2} P(1-P)
\end{gathered}
$$

where $G$ is the standard Gini index (James \& Taeuber 1985:5) and $G^{*}$ is the Gini index calculated if the workers (with minority proportion $P$ ) were randomly distributed to the firms (with given sizes) ${ }^{3}$.

\footnotetext{
2 Although Freeman developed this index to measure segregation in social networks with undirected links, it can be easily shown that it is also valid for directed links.

${ }^{3} \mathrm{G}^{*}$ can be calculated by simulating a random allocation of workers, with given $N$ and $P$, to a number of firms $F$, with specified size distribution. The value of $G^{*}$ used in subsequent
} 
The modified Gini index is more suitable than the standard Gini index or other indexes which measure the deviation of the distribution of workers from proportional distribution (the case in which all social groups are proportionally represented in all firms), for two reasons. Firstly, we are interested in simulating a labour market with small-to-medium sized firms (which increases the possibility of getting a high Gini index with a complete random allocation of workers). Secondly, we are particularly interested in measuring the systematic rather than random changes in workplace and social segregation.

\subsection{Model Dynamics}

The simulation starts with creating an artificial society of a number of agents from two different groups with a random social network for each agent. A number of firms $F$ are created, each with a specified number of jobs $\theta_{f}$, and then agents are assigned randomly to firms. The final step of the initialization process is to calculate and plot statistics for this initial stage, which include mainly indexes of segregation for workplaces and social networks in addition to employment levels. Then at each time step:

1. Each working agent leaves its workplace with the proper probability (as given by formula (4))

2. Each firm hires a number of agents, either randomly (through formal channels) or through referrals from current workers, depending on the probability $R$.

3. Agents update their homophily levels (according to formula (2)) and their social networks. Each agent creates a link through the workplace (if the agent is employed), through other links and/or randomly with the proper probabilities $\left(L_{W}\right.$, $L_{N}$ and/or $L_{R}$ respectively).

4. Statistics are calculated and plotted.

\section{Simulation Results}

In the following we summarize the results of the simulation model ${ }^{4}$ for workplace segregation, social segregation and the unemployment levels of minority and majority groups. The results are based on the values of parameters presented in Table 1. Unless otherwise specified, each simulation experiment is based on 30 runs; each lasts for 500 time steps.

sections is the average of values obtained through simulating the random allocation of workers to firms in 200 simulation runs.

4 The model was written in Netlogo 4.0 developed by Wilensky, U., 1999, Center for Connected Learning and Computer-Based Modeling, Northwestern University, http://ccl.northwestern.edu/netlogo. 
Table 1. Parameters values and description for the simulation model.

\begin{tabular}{lll}
\hline Parameter & Description & Value \\
\hline General & & \\
$\alpha_{1}, \alpha_{2}, \alpha_{3}, \alpha_{4}$ and $\alpha_{5}$ & Constants regulating the change in homophily levels. & 0.4 \\
$\beta$ & A constant regulating workers turnover. & 0.1 \\
Agents & Total number of agents & 1000 \\
$N$ & Proportion of the minority (Red) group & 0.2 \\
$P$ & & \\
Social Networks & Size of social networks of agents & 10 \\
$S_{i}$ & Probability of creating a new link with other co-workers & 0.3 \\
$L_{W}$ & Probability of creating a new link through current links & 0.5 \\
$L_{N}$ & Probability of creating a new link randomly & 0.01 \\
$L_{R}$ & & \\
Workplaces & Number of firms & 40 \\
$F$ & Number of jobs in each firm & 20 \\
$\theta_{f}$ & A regulating scalar for hiring discrimination & 1 \\
discrimination-const &
\end{tabular}

\subsection{Referral Hiring, Workplace Segregation and Social Segregation}

The results summarized in Figure 2 show the co-evolution of workplace segregation and social segregation with different levels of referral hiring. Both workplace segregation and social segregation increase with increasing level of referral hiring. An interesting result is that significant levels of workplace segregation and social segregation may evolve even when hiring of workers occurs mainly through formal channels and the society is initially integrated. Figure 3 shows the levels of social and workplace segregation during one of the simulation runs with three levels of referral hiring $0.0,0.6$, and 1.0 (only three levels are considered to avoid the figure getting very crowded). The random allocation of workers to firms may introduce some level of workplace segregation which triggers an increasing (but still low) levels of homophily and social segregation which, in turn, promotes workplace segregation (through the exit patterns of workers), and so on. Higher levels of referral hiring make workplace composition more dependent on agents' social networks and promote this reciprocal reinforcement between social and workplace segregation; thus, pushing both to higher levels. 


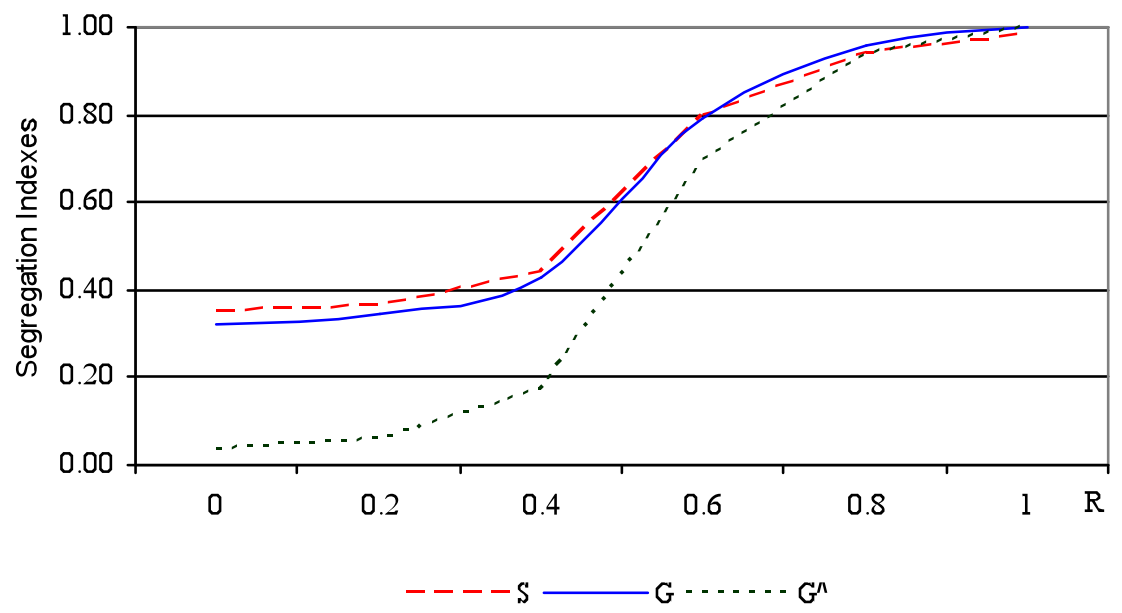

Figure 2. Co-evolution of workplace segregation $(G$ and $\hat{G})$ and social segregation $(S)$ for different levels of referral hiring $(R)$.

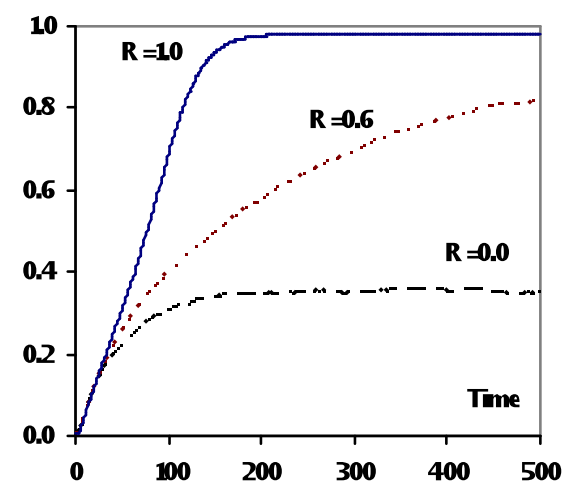

Social Segregation (S)

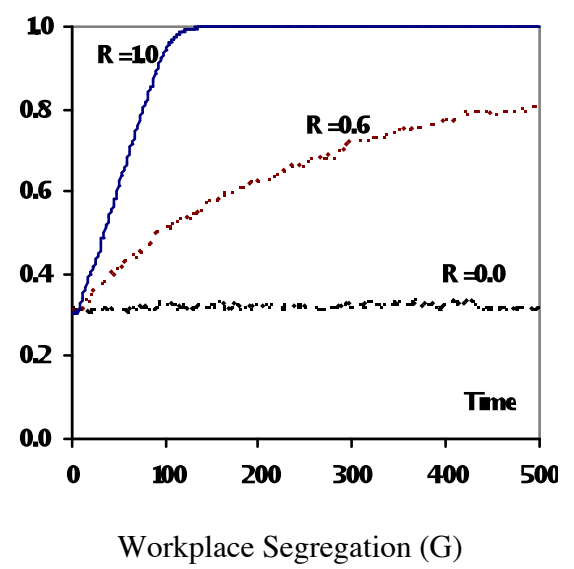

Workplace Segregation (G)

Figure 3. Co-evolution of workplace segregation and social segregation across time with different levels of referral hiring. 


\subsection{Homophily Levels}

The results of the simulation show that even when we start with a zero-level of homophily, agents of majority groups, generally, end with higher homophily levels than those of minority groups (as shown in Figure 4). The main reason is that minority people have a higher chance to have outgroup links (through social networks or workplaces) than majority group members. However, this difference in homophily levels vanishes gradually as the minority proportion increases.

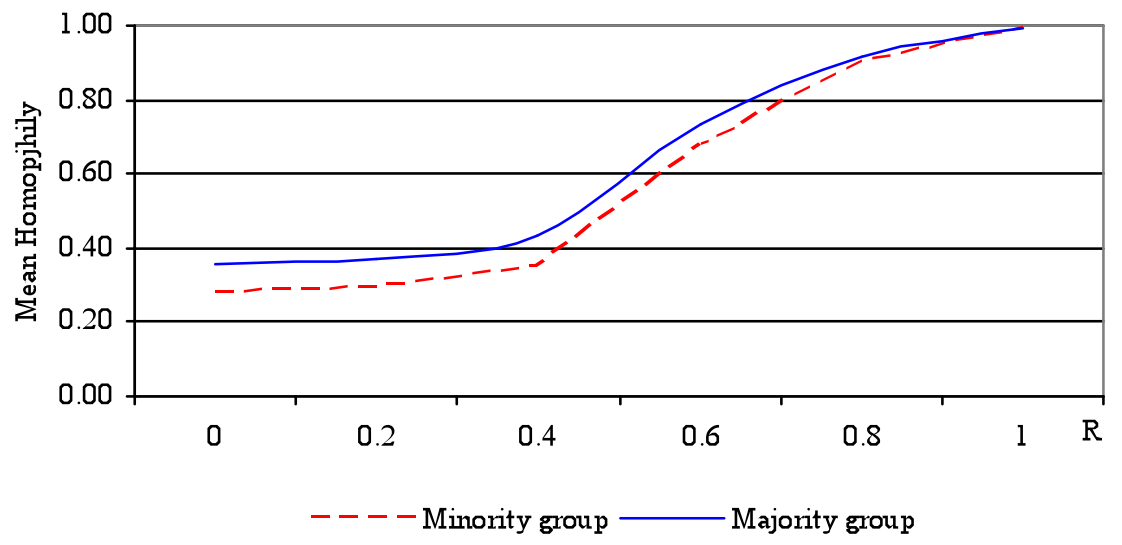

Figure 4. Final mean homophily levels for minority and majority groups for different levels of referral hiring $(R)$.

\subsection{Employment Inequality}

An interesting result of the simulation model is that increasing levels of referral hiring could be beneficial for minority groups when the population is highly segregated and harmful otherwise. As Figure 5 shows, minority unemployment generally decreases with increasing level of referral hiring until it reaches a minimum (with $R=0.8$ in our experiment) and then increases. When referral hiring is low (hence, lower levels of workplace and social segregation), all unemployed agents will have the same chance to join any workplace with vacant jobs, and will have the same 
probability to exit their workplaces, hence all social groups will have similar unemployment levels (around 20 percent in our experiments). This is clearly illustrated in Figure 6 with the case of $R=0$. But with higher levels of referral hiring (the cases $R=0.8$ and $R=1$ ), minority unemployment tends to be higher than majority unemployment at the early stage of the simulation while there are still low levels of workplace and social segregation. However, as time passes and segregation increases, referral hiring benefits the minority's employment. For example, when $R=0.8$, minority unemployment attains a stationary level of 16 percent. When level of referral hiring is close to one, a complete segregation of workplaces (and social networks) is reached, the firms are distributed proportionally between minority and majority groups, and all groups have the same unemployment level (20 percent).

This relationship between referral hiring and minority employment is consistent with Tassier and Menczer's (2008) model where they show that:

"more random social networks [majority groups] yield higher employment rates than less random social networks [minority groups] if the population is integrated [in early stage of our simulation] or information flows about job vacancies are random [low level of referral hiring]. However if the population is highly segregated and information flows about job vacancies are non-random [with high level of referral hiring in later stages of simulation run] then less random social networks have higher employment rates than more random social networks. This second finding holds because non-random social networks allow a group to better contain job information inside the group when a population is segregated.” (p. 1)

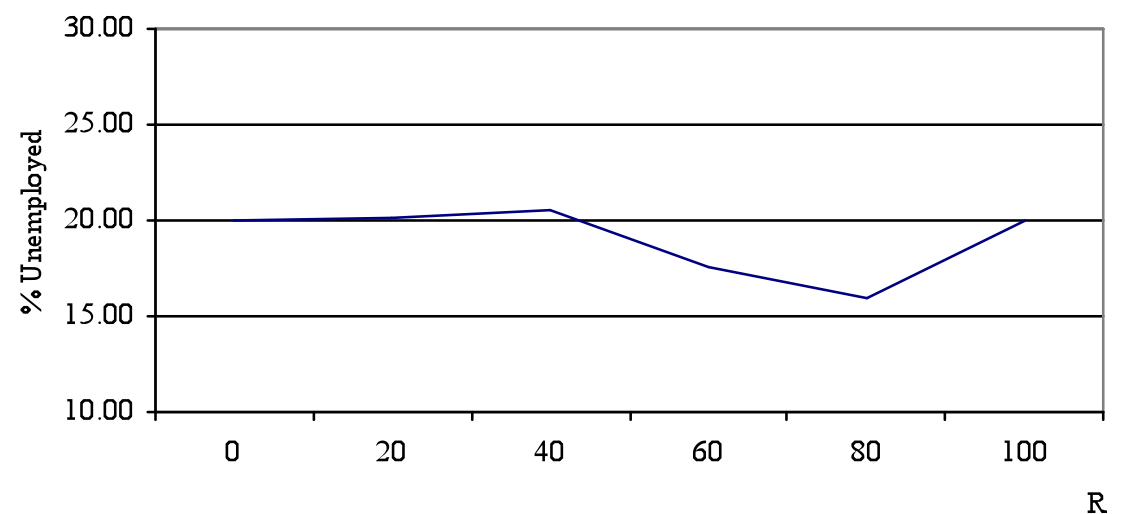

Figure 5. Unemployment levels of minority group for different levels of referral hiring, $R$. 


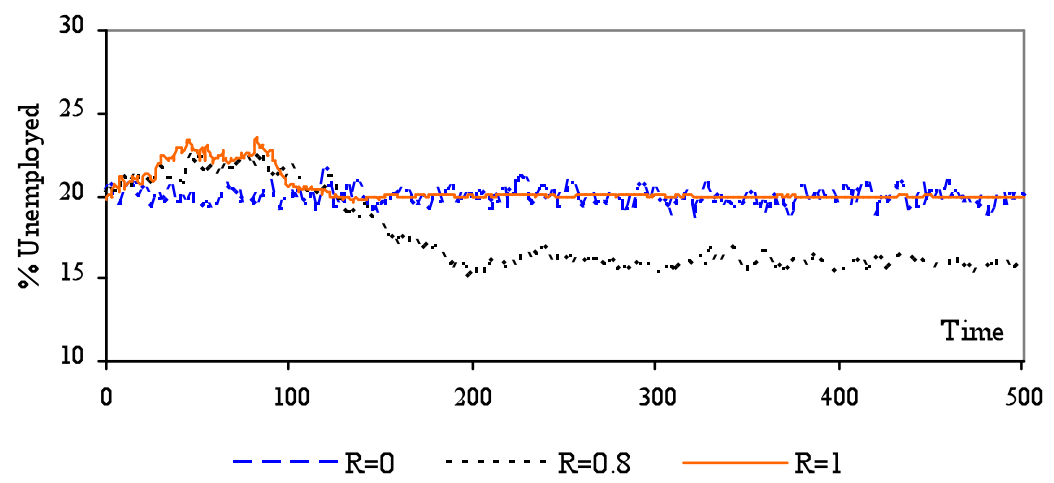

Figure 6. Unemployment levels of minority group across time with $R=0,0.8$ and 1 .

\subsection{Minority Proportion and Segregation}

Increasing the proportion of the minority group might be expected to decrease social and workplace segregation. As Figure 7 shows, there is a negative relationship between the proportion of the minority and social and workplace segregation. With a larger minority, the probability for individuals to have social links to others from a different social group increases and this decreases social and workplace segregation. The proportion of minority also affects the level of segregation at the initial stages of the simulation. As described earlier, mere random allocation of workers to jobs, during the initial stages of simulation, creates some level of workplace segregation, and this level increases as the proportion of the minority decreases.

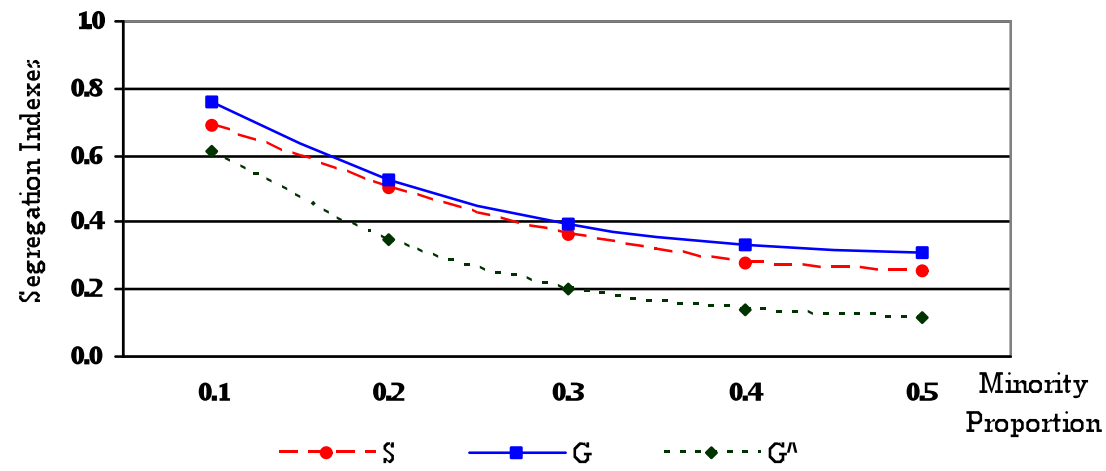

Figure 7. The effect of minority proportion on workplace segregation $\left(G\right.$ and $\left.G^{\wedge}\right)$ and social segregation $(S)$ 


\subsection{Firms' Sizes and Segregation}

Many empirical studies suggest that there is negative relationship between firm sizes (measured by number of workers) and workplace segregation (for example: Sørensen 2004, Holzer 1998). Most of these studies argue that large firms may be less segregated because they are subject to more regulation and oversight about hiring practices. The main concern of the current simulation experiment is to answer the following question: would this negative relationship between firm size and segregation still exist even when all firms follow the same hiring practices (in other words, when we control for hiring practices)?

As presented in Figure 8, the simulation results show that there is a strong negative relationship between average firms' sizes and social and workplace segregation even when all firms are assumed to follow the same hiring practices (all firms use referral hiring with the same probability, $R$ ). This negative relationship could be explained by two factors. Firstly, larger firms have lower levels of segregation at the initial stages of the simulation. Secondly, in larger firms, there is a greater chance that they will have workers from different social groups proportionally represented, which in turn increases the probability for social links to be established among these workers, and this decreases both social and workplace segregation.

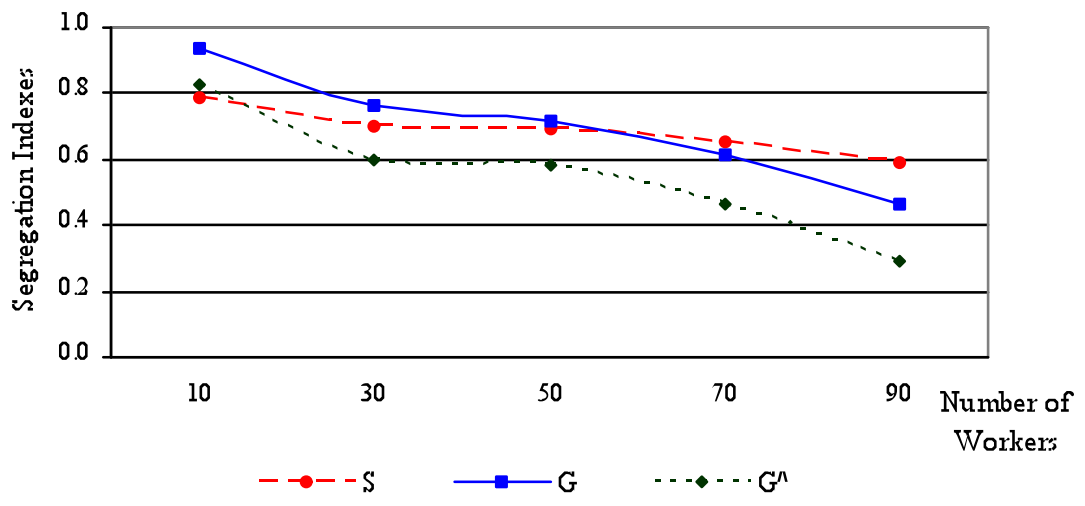

Figure 8. The effect of firm size on workplace segregation $\left(G\right.$ and $\left.\mathrm{G}^{\wedge}\right)$ and social segregation $(S)$. 


\section{Model Validation}

The model's behaviour was checked against data describing the Egyptian labour market and social networks. Egypt can be divided into a majority Muslim population and a 6 percent minority of Coptic Christians. Three sources of data were used to estimate the model's parameters:

1. Social Contract Survey (SCS) (Information and Decision Support Centre, the Egyptian Cabinet, 2005, unpublished data). SCS was carried out in 17 of the 26 Egyptian governorates. It involved structured interviews with 6006 household representing 29,417 individuals. As Table 2 shows, SCS was used to estimate the proportion of the Coptic minority, the overall unemployment rate, and unemployment rates for Muslims and Copts.

2. Workers' Status in Industrial Enterprises Survey (WSIES) (Social Research Centre, American University in Cairo, 2005, unpublished data). WSIES was used to assess the status of workers in industrial enterprises. The survey's sample included 324 randomly-chosen industrial enterprises with 10 or more employees in each; 2694 male workers and 646 female workers. The sample covered six governorates: Cairo, Alexandria, Sharkkia, Gharbia, Kalubia and Giza. WSIES data provided estimates for numbers of workers, firms, jobs, Coptic employers, and Muslim employers (Table 2), in addition to estimates of workplace segregation (Table 3).

3. Empirical Data (ED) gathered by the first author. These data involved structured interviews with a subsample from the WSIES with 39 employers (owners or mangers of small-to-medium industrial firms), and 122 workers ( 81 Muslim and 41 Coptic) in four Egyptian governorates: Cairo, Alexandria, Sharkkia, and Kalubia. Employer interviews provided data about firm's religious composition, recruitment practices, and hiring discrimination. Worker questionnaires provided information about social networks' sizes, structure, and composition, and how they were used for job search.

Table 2 presents the values for the model's parameters estimated from these three data sources. 
Table 2. Estimated values for model's parameters based on data about social networks and workplaces in Egypt.

\begin{tabular}{lll}
\hline Parameter Name & Parameter Value & Source \\
\hline Minority proportion $(P):$ & 0.06 & SCS \\
Overall unemployment rate & 0.13 & SCS \\
Number of workers $(N)$ & 4800 & WSIES \\
Number of firms $(F)$ & 165 & WSIES \\
Total number of jobs & 4176 & WSIES \\
Number of jobs in each firm $\left(\theta_{f}\right)$ & Same distribution as WSIES & WSIES \\
Number of Coptic employers & 14 & WSIES \\
Number of Muslim employers & 151 & WSIES \\
discrimination-const & 0.7 & WSIES \\
Level of referral hiring & 0.65 & ED \\
$L_{W} L_{N}$ and $L_{R}$ & $0.3,0.5,0.01$ (respectively) & ED \\
Maximum network size of agents $\left(S_{i}\right)$ & Normal $(8,3)$ & ED \\
\hline
\end{tabular}

The results presented in Table 3 show that there a close similarity between the observed and the simulated values. All confidence intervals (CIs) of the difference between of the observed and simulated values contain the zero point, indicating that they are not significantly different.

Table 3. Comparing observed and simulated values of variables in the simulation model.

\begin{tabular}{lcccc}
\hline Variable Name & $\begin{array}{c}\text { Observed } \\
\text { Value }\end{array}$ & $\begin{array}{c}\text { Simulation } \\
\text { Value }\end{array}$ & $\begin{array}{c}\text { Std. } \\
\text { Error }\end{array}$ & $\begin{array}{c}\text { 95\% CI of } \\
\text { Difference }\end{array}$ \\
\hline Social Segregation & 0.802 & 0.796 & 0.004 & $(-0.013,0.001)$ \\
Workplace Segregation - Gini & 0.932 & 0.925 & 0.003 & $(-0.0136,0.0002)$ \\
Muslims unemployment & 0.133 & 0.1334 & 0.0002 & $(-0.0008,0.0009)$ \\
Copts unemployment & 0.079 & 0.074 & 0.003 & $(-0.011,0.002)$ \\
\hline
\end{tabular}

\section{Conclusion}

In this paper we introduced a general framework to describe the dynamic relationships between social segregation, workplace segregation, homophily levels, and referral hiring, and formalised the framework as an agent-based simulation model. The model was validated against data from the Egyptian labour market and social networks. The simulation indicated that the labour market may experience significant levels of workplace segregation and social segregation even when hiring of workers occurs mainly through formal channels. The results also show that minority groups tend to be more homophilous than majority groups, that referral hiring may be beneficial for minority groups especially when the population is highly segregated, and that the relationship between referral hiring and minority unemployment is not 
linear. Levels of workplace and social segregation were found to be negatively correlated with the proportion of the minority and with firm size.

\section{Acknowledgments}

We thank the two anonymous referees for their useful comments and suggestions. We gratefully acknowledge the sponsorship of the Egyptian Ministry of Higher Education through its scholarship scheme.

\section{References}

Allport GW (1954) The Nature of Prejudice. Addison-Wesley, Cambridge

Amir Y (1969) Contact Hypothesis in Ethnic Relations. Psychol Bull 71:319-342

Becker GS (1971) The Economics of Discrimination. The University of Chicago Press, Chicago

Blanchard FA, Weigel RH, Cook SW (1975) The effect of relative competence of group members upon interpersonal attraction in cooperating interracial groups. J Pers Soc Psychol 32:519-530

Brown R (1995) Prejudice: Its Social Psychology. Blackwell, Oxford

Calvó-Armengol A, Jackson MO (2004) The Effects of Social Networks on Employment and Inequality. Am Econ Rev 94:426-454

Calvó-Armengol A, Jackson MO (2007) Networks in labor markets: Wage and employment dynamics and inequality. J Econ Theory 132:27-46

Carrington WJ, Troske KR (1997) On Measuring Segregation in Samples with Small Units. J Bus Econ Statist 15:402-409

Carrington WJ, Troske KR (1998) Interfirm Segregation and the Black/White Wage Gap. J Labor Econ 16:231-260

Cook SW (1978) Interpersonal and Attitudinal Outcomes in Cooperating Interracial Groups. J Res Dev Educ 12:97-113

Elliott JR (2001) Referral Hiring and Ethnically Homogeneous Jobs: How Prevalent Is the Connection and for Whom? Soc Sci Res 30:401-425

Ellison CG, Powers DA (1994) The Contact Hypothesis and Racial Attitudes among Black Americans. Soc Sci Q 75:385-400

Emerson MO, Kimbro RT, Yancey G (2002) Contact Theory Extended: The Effects of Prior Racial Contact on Current Social Ties. Soc Sci Q 83:745-761

Fischer CS (1982) To Dwell Among Friends. University of Chicago Press, Chicago

Freeman LC (1978) Segregation in Social Networks. Sociol Methods Res 6:411-429

Gemkow S, Neugart M (2008) Referral Hiring, Endogenous Social Networks, and Inequality: An Agent-Based Analysis. Conf European Social Simulation Association, Brescia

Gilbert N, Troitzsch KG (2005) Simulation for the social scientist. Open University Press, Milton Keynes

Glass J (1990) The Impact of Occupational Segregation on Working Conditions. Soc Forces 68:779-796

Granovetter MS (1973) The Strength of Weak Ties. Am J Sociol 78:1360-1380

Granovetter MS (1995) Getting a Job: A Study of Contacts and Careers. University of Chicago Press, Chicago

Grossetti M (2005) Where do social relations come from? Soc Networks 27:289-300

Harding J, Hogrefe R (1952) Attitudes of white department store employees toward Negro coworkers. J Soc Issues 8:18-28

Holzer HJ (1998) Why Do Small Establishments Hire Fewer Blacks Than Large Ones? J Hum Resour 33:896-914 
Ioannides YM, Loury LD (2004) Job Information Networks, Neighborhood Effects, and Inequality. J Econ Lit 42:1056-1093

Jackson MO (2004) A Survey of Models of Network Formation: Stability and Efficiency. In: Demange G, Wooders M (eds) Group formation in economics: Networks, clubs, and coalitions. Cambridge University Press, Cambridge, pp 11-88

James DR, Taeuber KE (1985) Measures of Segregation. Sociol Methodol 15:1-32

Krauth BV (2004) A dynamic model of job networking and social influences on employment. J Econ Dyn Control 28:1185-1204

Latane B (1981) The Psychology of Social Impact. Am Psychol 36:343-356

McCallister L, Fischer CS (1983) A Procedure for Surveying Personal Networks. In: Burt RS, Minor MJ (eds) Applied Network Analysis: A Methodological Introduction. Sage Publications, London, pp 75-88

McPherson M, Smith-Lovin L, Cook JM (2001) BIRDS OF A FEATHER: Homophily in Social Networks. Annu Rev Sociol 27:415-444

Minrad RD (1952) Race relations in the Pocahontas coal field. J Soc Issues 8:29-44

Morrison EW, Herlihy JM (1992) Becoming the best place to work: Managing diversity at American Express Travel related services. In: Jackson SE (ed) Diversity in the workplace. Guilford Press, New York, pp 203-226

Mouw T (2002) Are Black Workers Missing the Connection? The Effect of Spatial Distance and Employee Referrals on Interfirm Racial Segregation. Demography 39:507-528

Pettigrew TF (1998) Intergroup Contact Theory. Annu Rev Psychol 49:65-85

Robinson JL (1980) Physical Distance and Racial Attitudes: A Further Examination of the Contact Hypothesis. Phylon 41:325-332

Schelling TC (1971) Dynamic models of segregation. J Math Sociol 1:143-186

Sigelman L, Welch S (1993) The Contact Hypothesis Revisited: Black-White Interaction and Positive Racial Attitudes. Soc Forces 71:781-795

Sørensen JB (2004) The Organizational Demography of Racial Employment Segregation. Am J Sociol 110:626-671

Tassier T, Menczer F (2008) Social Network Structure, Segregation, and Equality in a Labor Market with Referral Hiring. J Econ Behav Organ 66:514-528

Tassier T (2005) A Markov Model of Referral-Based Hiring and Workplace Segregation. J Math Sociol 29:233-262

Tassier T (2008) Referral Hiring and Gender Segregation in the Workplace. East Econ J $34: 429-440$

Watts DJ, Strogatz SH (1998) Collective dynamics of 'small-world' networks. Nature 393:440442

Watts DJ (1999) Small World Networks: The Dynamics of Networks between Order and Randomness. Princeton University Press, Princeton

Williams JA (1964) Reduction of Tension through Intergroup Contact: A Social Psychological Interpretation. Pac Sociol Rev 7:81-88

Yancey G (1999) An Examination of the Effects of Residential and Church Integration on Racial Attitudes of Whites. Sociol Perspect 42:279-304 